ECCOMAS

\section{Proceedia}

COMPDYN 2021

$8^{\text {th }}$ ECCOMAS Thematic Conference on Computational Methods in Structural Dynamics and Earthquake Engineering M. Papadrakakis, M. Fragiadakis (eds.) Streamed from Athens, Greece, 28 - 30 June 2021

\title{
FINITE ELEMENT MODEL CALIBRATION EFFECTS ON THE STATIC AND DYNAMIC RESPONSE OF A METALLIC HOLLOW TOWER
}

\author{
Dick Anelise $^{1}$, Carneiro-Barros Rui ${ }^{1}$, and Braz-César T. Manuel $^{2}$ \\ ${ }^{1}$ CONSTRUCT, Faculdade de Engenharia, Universidade do Porto \\ FEUP, Porto, Portugal \\ \{anelise.dick, rcb\}@fe.up.pt \\ ${ }^{2}$ CONSTRUCT, Instituto Politécnico de Bragança \\ IPB, Bragança, Portugal \\ brazcesar@ipb.pt
}

\begin{abstract}
Analysis and modeling of structures, under the influence of dynamic loads, is usually carried out through the application of the finite element method (FEM). These analyses are intrinsically dependent on the parameters considered in the model, and the parameters must translate the real properties of the structure so that the model's behavior is reliable as compared wih the physical behavior of the structure; for these purposes the model calibration using experimental data aims to improve the uncertainty of model parameters or inaccuracies in modeling.

In the present work a numerical analysis was carried out, on a small wind turbine metallic hollow tower with hexa-decagon section and $17.80 \mathrm{~m}$ high, applying the finite element theory with SAP2000® software. The FEM model was updated with the frequency results of in-situ vibration tests; to compare the results, two methods Experimental Modal Analysis (EMA) and the Operational Modal Analysis (OMA) were applied in the experimental tests to evaluate the dynamic properties of the tower.

It is noticed that the first frequency of the model without calibration has a value of $2.129 \mathrm{~Hz}$ that is $32,2 \%$ above the real measured $1.610 \mathrm{~Hz}$; after calibration update, the first frequency of the tower has a value of $1.590 \mathrm{~Hz}$ consistent with the results of the vibration tests. The static response of the structure to loading at the top, also shows a significant difference between the uncalibrated and the calibrated model: after calibration there is a 25\% increase in displacement at the top of the structure; the compression force is the one with the smaller differences, while the base shear and base moments increased tremendously but maintained the location of points of maximum stresses.
\end{abstract}

Keywords: Finite element model calibration; Ambient vibration test; Impact hammer test; hollow tapered tower; Small wind turbine tower. 


\section{INTRODUCTION}

Developing and improving sustainable and affordable energy production systems is one of today's engineering concerns. Wind energy is one of the sources of renewable energy that has been recently continuously studied, also with the purpose of optimizing the costs of installation and production. The wind turbine tower WTT is a part of the system that affects production efficiency and is usually a slender and flexible structure; it is considered the critical part of the wind turbine, since it should support the dead loads of equipment and additional loads caused by wind. The wind turbine tower has two crucial functions: supports in the height the rotor nacelle system in the height and transfer the loads' actin on the structure to the foundation.

The analysis and modeling of these type of structures, under the influence of dynamic loads, is usually achieved through analytical computational modeling techniques, on the application of the finite element method (FEM). These analyses are intrinsically dependent on the values chosen for the parameters considered in the model, which must translate the real properties of the structure so that the model's behavior is reliable as the physical behavior of the structure.

In complex structures, the model generally consists of some simplification of the structure, but it must adequately represent the real structure; so there is a need to validate the numerical model with test results in real structures, to adjust the parameters used. Adjusting the analytical model using experimental data is known as model calibration in structural dynamics, and aims to improve the uncertainty of model parameters or inaccuracies in modeling.

To determine the dynamic characteristics of a structure, there are two experimental methods accessible: Experimental Modal Analysis (EMA) and Operational Modal Analysis (OMA); and the main difference between these methods, is the need or not for a controlled excitation source. In EMA, it is necessary to know the excitation force and the response of the structure; on the other hand, in OMA only the response of the structure is measured. In fact, for general structures OMA is largely more applied -- as in bridges [1]-[7], tall or quite specific buildings [8]-[11] and towers [12]-[14] - for example through structural health monitoring associated with series of ambient vibration measurements.

In the case of dynamic excitations in towers of major wind turbines, there are several studies in the bibliography that compared analytical and experimental results [15]-[18]; for such it is common to use the NREL 5MW wind turbine as the object of study [19]-[22], and then apply different techniques of dynamic tests and structural monitoring.

However, when it comes to small wind turbines, those that have a rotor swept area smaller than $200 \mathrm{~m}^{2}$, comparative studies are limited. Castellani et al. [23] calibrated and updated the parameters of a small wind turbine using the power spectra density, function of major excited frequencies, evaluated with an impact hammer test in a prototype tower for wind tunnel test; but in his work, the main objective was the study of the wind turbine. In the present work a numerical analysis was carried out, on a small wind turbine metallic hollow tower with hexadecagonal section and 17.80 meters high, applying the finite element method with SAP2000 software and using the results of dynamic vibration tests in the real tower to calibrate the model.

\section{DESCRIPTION OF THE TOWER}

The analyzed metal tower is located at the School of Technology and Management of the Polytechnic Institute of Bragança (Portugal), consists of a steel structure with the height of $17.81 \mathrm{~m}$, having a hexa-decagonal section with an outside diameter of $0.5890 \mathrm{~m}$ at the base and $0.1954 \mathrm{~m}$ at the top, and with constant wall thickness of $4 \mathrm{~mm}$. The tower is fixed to the gravitybase foundation by 16 anchor bolts connected to a flange at the base; the flange has an external diameter of $0.7960 \mathrm{~m}$ and a thickness of $20 \mathrm{~mm}$. 
The designed tower structure has a straight geometric configuration as shown in Fig. 1 (a); but the real tower structure presents an initial out-of-straightness with a total offset of $0.122 \mathrm{~m}$ at the top in relation to the axis of the tower, as shown in Fig. 1 (b). The tower is produced from S275 steel whose properties and design characteristics were established in accordance with the Eurocode 3 [24]; considering the thickness $\mathrm{t} \leq 4 \mathrm{~mm}$, the properties are shown in Table 1 . The computational simulations using FEM considered the linear behavior of the material.
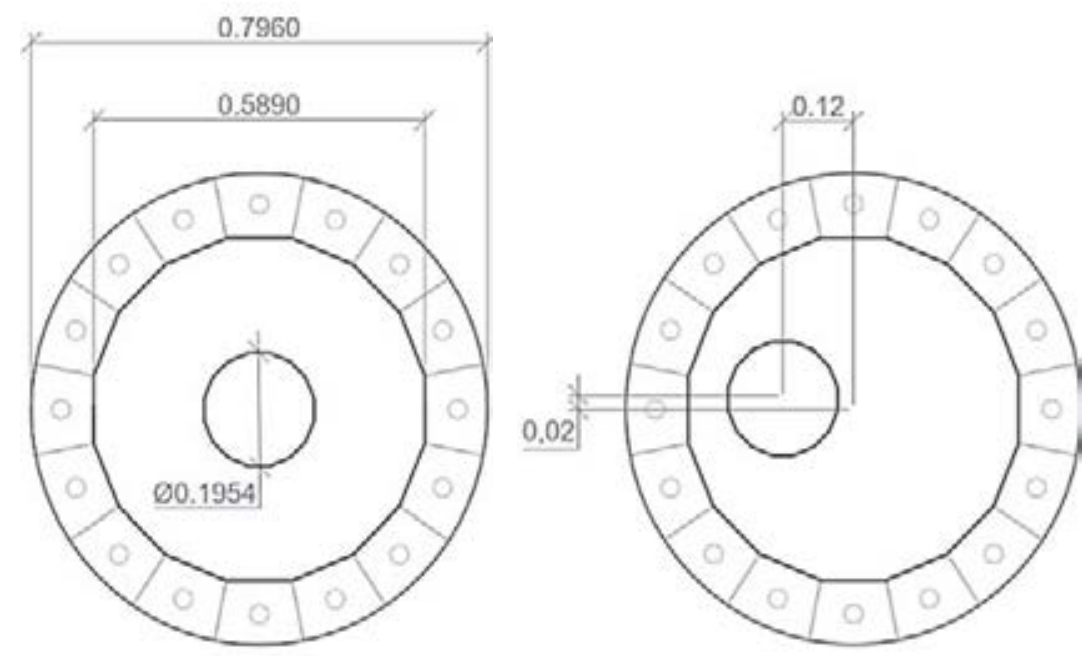

Figure 1. Tower geometries. (a) Straight tower, (b) Crooked tower.

\begin{tabular}{l|l|l}
\hline & \multicolumn{2}{|c}{ Linear } \\
\hline Density & 7850 & {$\left[\mathrm{~kg} / \mathrm{m}^{3}\right]$} \\
\hline Young's modulus & 210 & {$[\mathrm{GPa}]$} \\
\hline Poisson's ratio & 0.3 & -- \\
\hline Yield strength & 275 & {$[\mathrm{MPa}]$} \\
\hline Ultimate strength & 430 & {$[\mathrm{MPa}]$} \\
\hline
\end{tabular}

Table 1 : Steel S275 properties.

\subsection{In situ vibration measurement}

To determine the dynamic characteristics of the structure two methods were applied in the studied tower: EMA and OMA.

Measurements associated with the experimental modal analysis were carried out using: a data acquisition system composed of NI USB-4431 data acquisition board with 4 input channels, 24-bit ACD resolution, sampling rate from $1 \mathrm{kS} / \mathrm{s}$ to $102.4 \mathrm{kS} / \mathrm{s}$, resolution $2.10 \mathrm{mS} / \mathrm{s}$; piezoresistive accelerometer ICP ${ }^{\circledR}$ with a frequency range from 0.5 to $2000 \mathrm{~Hz}$; and a laptop with SignalExpress (C) software.

Firstly, the dynamic load test was performed with two accelerometers placed at 1.41 meters high in two distinct perpendicular directions ( $\mathrm{x}$ and $\mathrm{y}$ ). The input excitation force is caused by the impact hammer PCB 086b20. The first (and others, if required) natural frequency is defined by the peak-picking technique.

The power spectra density (PSD) functions associated with this EMA is presented in Figure 2(a) for the x-direction and in Figure 2(b) for the y-direction. 
The average values of the first three eigenfrequencies, in one direction, were obtained: 1.610 $\mathrm{Hz}$ for the first natural vibration frequency, $5.990 \mathrm{~Hz}$ for the second natural frequency, and $8.010 \mathrm{~Hz}$ for the third natural frequency.

As the structure is mainly symmetric, these frequencies for the two measured directions ( $\mathrm{x}$ and y) are practically considered the same, as is possible to verify in the given PSD's.
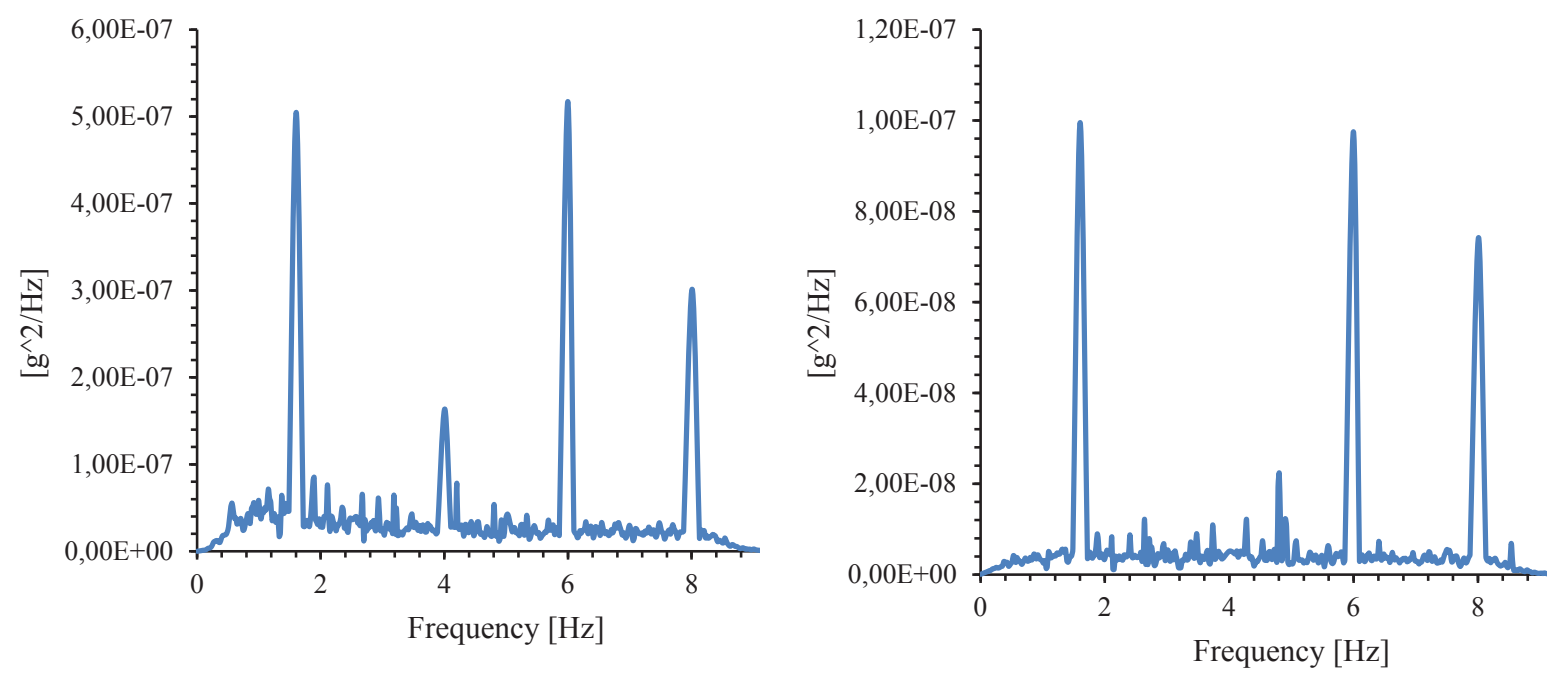

Figure 2 : PSD -- EMA. (a) x-direction, (b) y-direction

The ambient vibration testing associated with OMA was carried out for 20 minutes records, with the same location of the two accelerometers, and was executed three times. During the test, the average wind speed was $1.333 \mathrm{~m} / \mathrm{s}$ in the SWW direction, with a peak velocity of 4.92 $\mathrm{m} / \mathrm{s}$ in the S direction. As it is possible to verify in the PSD's presented in Figure 3, the external excitation was not capable to excite all the range of structural frequencies, so it is only possible to determine the first frequency that is congruent with the EMA results.
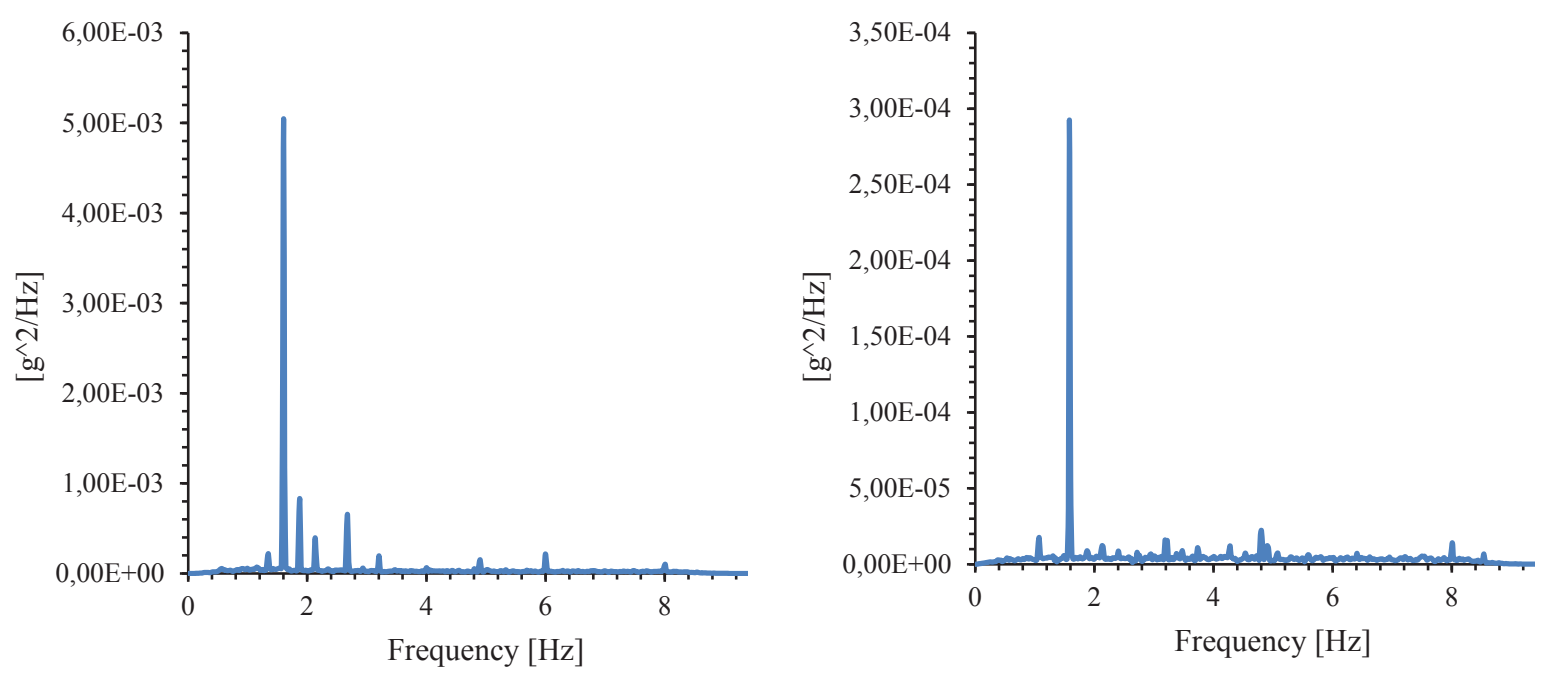

Figure 3 : PSD -- OMA. (a) x-direction, (b) y-direction 


\section{NUMERICAL MODEL}

The analysis of the structure using the Finite Element Method (FEM) is performed using the SAP2000 software. Initially, the model consists of a straight tower with the geometry presented above, including wind turbine's weight as a static boundary condition corresponding to a concentrated mass at the top of the tower. The boundary conditions assumed in the analysis must be chosen in such a way as to guarantee and achieve a realistic or conservative model of the actual structure. According to Eurocode 3 - Part 1-6 [3] the upper extremity is a free boundary condition (type $\mathrm{BC} 3$ ), and for the first model the lower extremity boundary condition is considered rigid (type BC1r, infinity support for which any type of movement is prevented).

Although FEM is a powerful tool for engineers, some aspects need to be verified carefully and the refinement of the mesh should be checked to avoid unrealistic local behavior; also the mesh should satisfy the so-called patch test. Figure 4 displays the frequency convergence of the model according to the number of elements, so the ideal mesh for the first FEM model divides the tower into 76800 elements; for such first model the converged fundamental frequency was evaluated as $2.12965 \mathrm{~Hz}$.

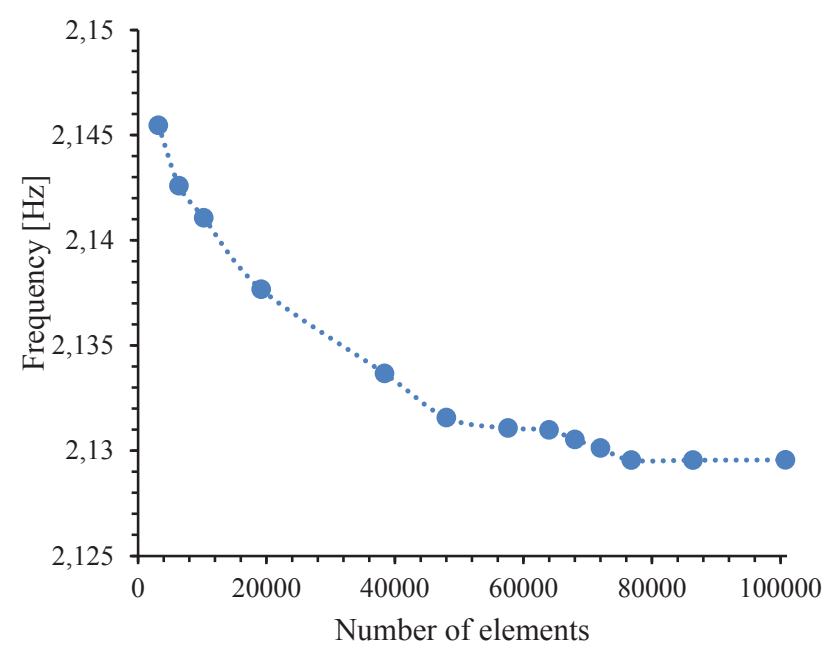

Figure 4 : Frequency convergence

\subsection{Finite element method model updating procedure}

The FEM model generally consists of a simplification of the structure, corresponding to some assumptions made, but it must adequately represent the real structure; so there is a need to validate the numerical model with test results in real structures, to adjust the parameters used. The procedure of adjusting the analytical or computational model using experimental data is known as a model calibration or model updating in structural dynamics; it aims to improve the uncertainty of model parameters or inaccuracies in modeling, that originate the uncertainties in simplifying assumptions of the structural geometry, materials, and even of inaccurate boundary conditions [25].

The comparison between the results of the experimental dynamic tests (EMA-OMA), the initial FE model and the updated FE models, are shown in Table 2.

\begin{tabular}{c|c|c|c|c|c}
\hline & Experimental & Initial FEM & $\mathbf{1}^{\text {st }}$ update & $\mathbf{2}^{\text {nd }}$ update & $\mathbf{3}^{\text {rd }}$ update \\
\hline First frequency [Hz] & 1.610 & 2.129 & 1.732 & 1.724 & 1.590 \\
\hline Second frequency [Hz] & 5.990 & 8.881 & 7.668 & 6.898 & 6.330 \\
\hline
\end{tabular}

Table 2 : Results of experimental and analytical modal identification and modification of structure parameters 
As the first frequency of the model $2.12965 \mathrm{~Hz}$ does not match with the measured $1.61 \mathrm{~Hz}$ frequency, the first model update was the inclusion of the flange and the change of the lower boundary condition, applying boundary condition of the type BC1f [26] (only rotation is free) in the location of the 16 bolts. The second updating was the consideration of the out-of-straightness of the tower and the eccentricity of the wind turbine. Even though the frequency is still above the real one, as the structure presents a service ladder and its equivalent mass was not considered in the numerical model, it is responsible for altering the inertia of the structure; so the last change or third updating, was to consider that equivalent mass through a factor. Now the first frequency of the model is the same as the measured one, and the model is considered calibrated. Even though the second frequency is not exact, it is very close and the final upgrade of the initial FE model produced a quite good agreement with the experimental results. The first frequency value shows a reduction about $25 \%$ from de non calibrated model to the calibrated one, and in Figure 5 it is possible to observe the change in the form of the mode shapes.
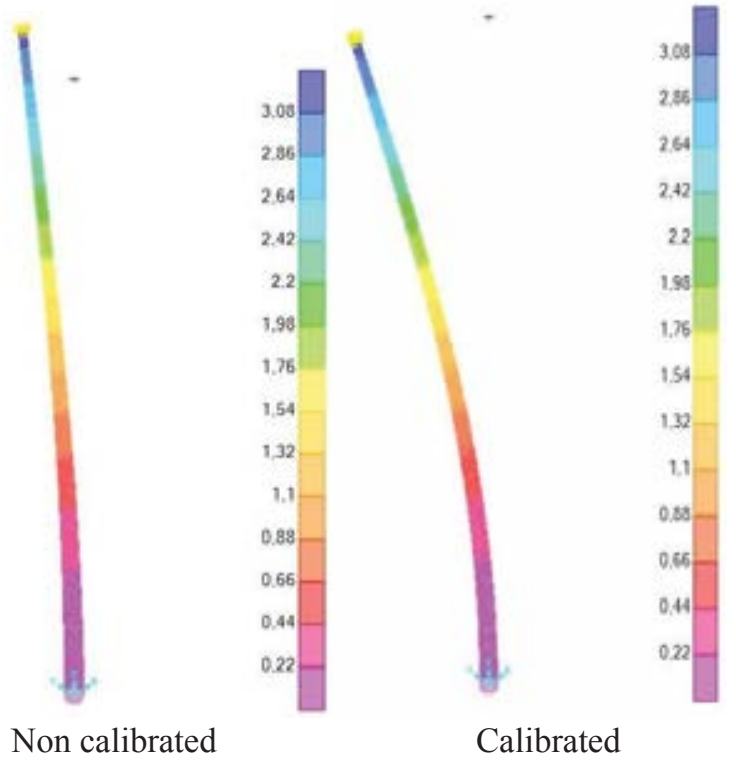

(a)

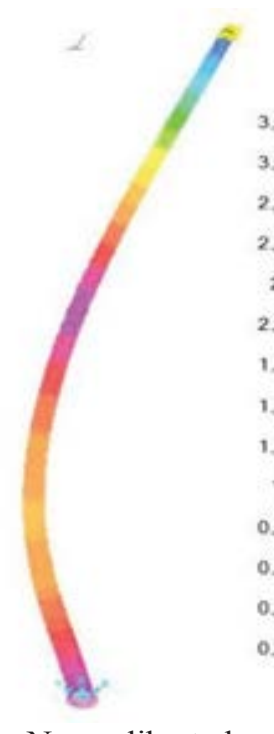

Non calibrated

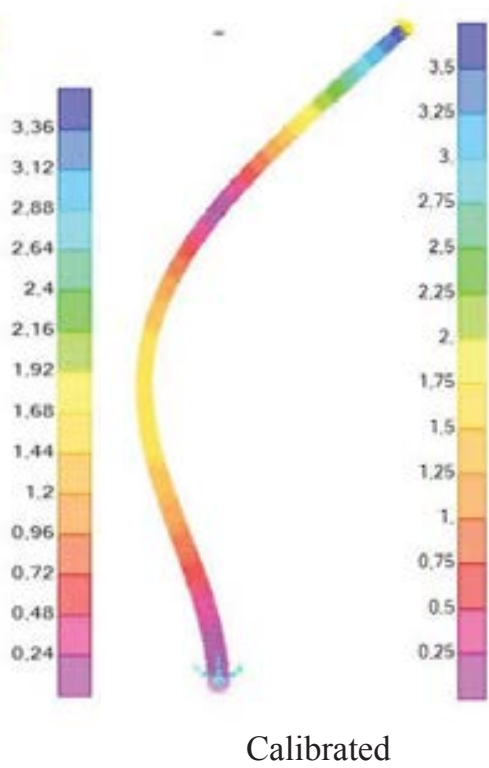

(b)

Figure 5 : Changed form of the mode shapes. (a) first mode, (b) second mode 


\subsection{Static analysis}

To evaluate the effects of the calibration upgrading in a static analysis, the external forces acting on the top of the tower that are induced by the wind turbine were determined according to DNV guidelines [27]. For simplification, the wind force acting laterally on the tower was not considered in this analysis.

The aerodynamic drag force produced by the blades on the top of the tower can be predicted by simplified calculations based on the projected area perpendicular to the flow. The rotor loads are expressed by three load quantities: static horizontal airflow (Eq. 1), driving torque (Eq.2) and weight of the rotor.

$$
\begin{gathered}
F_{0}=300 \cdot A \\
M_{e, n o m}=\frac{P_{n o m}}{2 \pi n_{I} \eta}
\end{gathered}
$$

where A is the swept area of the rotor in $\left(\mathrm{m}^{2}\right), P_{n o m}$ is the nominal power of the wind turbine, $n_{I}$ is the rotor frequency and $\eta$ the nominal efficiency.

The wind turbine supported by the tower is a Fortis Passat $(1.4 \mathrm{~kW})$ and the characteristics

\begin{tabular}{|c|c|c|c|}
\hline \multicolumn{4}{|c|}{ Fortis Passat (1.4 kW) } \\
\hline Gravitational acceleration & $g$ & 9.8066 & {$\left[\mathrm{~m} / \mathrm{s}^{2}\right]$} \\
\hline Rotor blade radius & $r$ & 1.5 & {$[\mathrm{~m}]$} \\
\hline Area of rotor & $A$ & 7.65 & {$\left[\mathrm{~m}^{2}\right]$} \\
\hline Rotor mass & $m$ & 75 & {$[\mathrm{~kg}]$} \\
\hline Rotor frequency & $n_{I}$ & 3 & {$[\mathrm{~Hz}]$} \\
\hline Nominal power of wind turbine & $P_{\text {nom }}$ & 1400 & {$[\mathrm{~W}]$} \\
\hline Nominal efficiency & $\eta$ & 0.7 & \\
\hline \multicolumn{4}{|l|}{ Calculations } \\
\hline Static horizontal airflow load & $F_{0}$ & 2295.000 & {$[\mathrm{~N}]$} \\
\hline Driving torque & $M_{e, n o m}$ & 106.103 & [N.m] \\
\hline \multirow[t]{2}{*}{ Eccentricity } & $e$ & 0.250 & {$[\mathrm{~m}]$} \\
\hline & \multicolumn{3}{|c|}{ Static load } \\
\hline Moment about horizontal axis rotor plane & $M_{x}$ & 573.750 & [N.m] \\
\hline Horizontal force along rotor axis & $F_{y}$ & 2295.000 & {$[\mathrm{~N}]$} \\
\hline Moment about axis rotor & $M_{y}$ & 137.934 & [N.m] \\
\hline Vertical force & $F_{Z}$ & -735.495 & {$[\mathrm{~N}]$} \\
\hline Moment about vertical axis & $M_{z}$ & 573.750 & [N.m] \\
\hline
\end{tabular}
are presented in Table 3 including static loads predicted on top of the tower.

Table 3 : Simplified load calculations on top of the tower

The structural analysis results shown in Table 4 for top displacements and generalized stress resultants, before and after model calibration updating and upgrading, indicate the differences between the correct calibrated model and the initial model; the most important differences occur for the maximum base shear force and the maximum and minimum base moments. 


\begin{tabular}{c|c|c|c}
\hline & Initial FEM & Final FEM & Difference (\%) \\
\hline First frequency [Hz] & 2.129 & 1.590 & -25.32 \\
\hline Top displacement [m] & 0.146683 & 0.196223 & 25.25 \\
\hline Fmax [kN] & 1156.488 & 1323.539 & 14.44 \\
\hline Fmin [kN] & -1213.27 & -1430.88 & 17.94 \\
\hline Vmax [kN] & 5.676 & 488.543 & 8507.17 \\
\hline Mmax [kN.m] & 0.101 & 17.997 & 17718.81 \\
\hline Mmin [kN.m] & -0.096 & -19.497 & 20209.38 \\
\hline
\end{tabular}

Table 4 : Comparison of results before and after model calibration updating

Figure 6 shows that the points of maximum stresses are the same in both models, however, the intensity of the stress is much larger in the calibrated model.
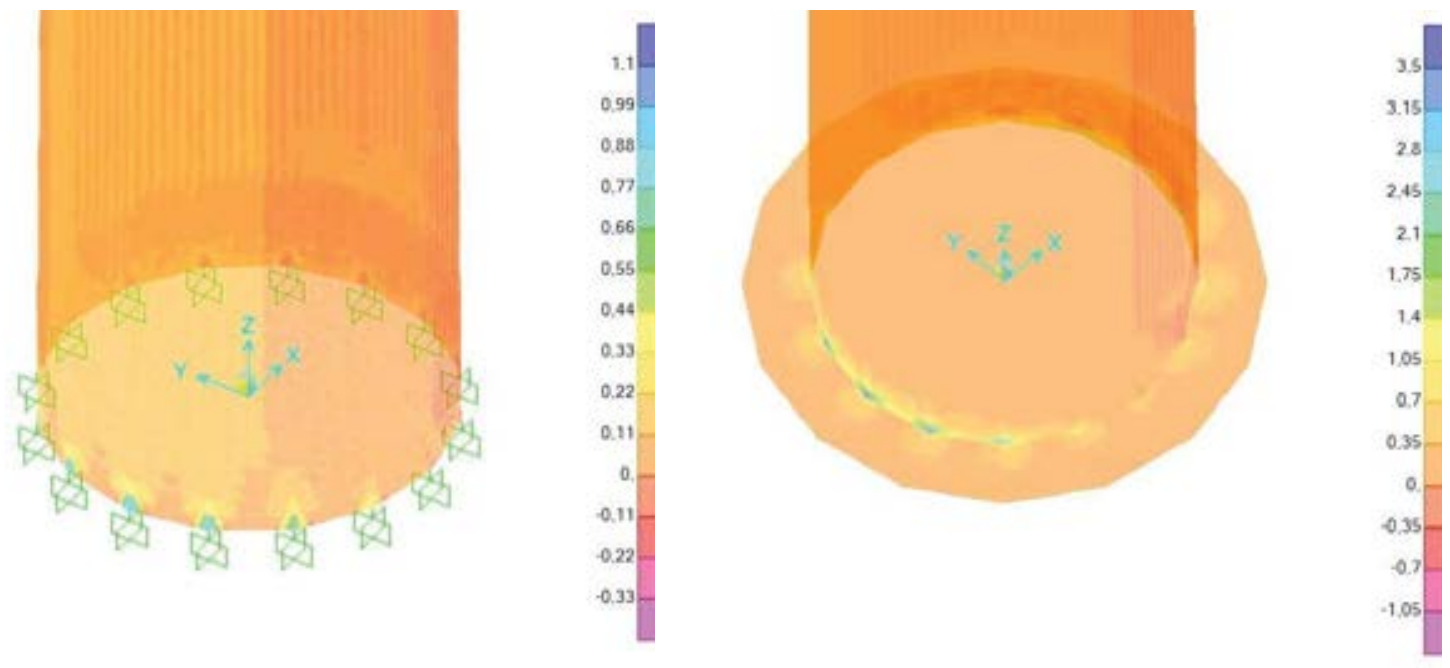

Figure 6 : Normalized maximum stress. (a) non calibrated, (b) calibrated model.

\section{CONCLUSIONS}

In this paper, modal testing and finite element model updating of a steel hollow tapered tower were presented. A 3D finite element model of the tower was developed using the SAP2000 software. Dynamic tests were performed using the impact hammer technique and also ambient vibration testing, in order to extract the natural frequencies of the tower. The FEM model was calibrated changing the boundary conditions, but also including some geometric characteristics complemented by better detailing of some uncertain modeling parameters.

Based on the results of this study, the following conclusions can be made with respect to differences in dynamic characteristics: reduction of $25 \%$ in the first natural frequency of the tower from the initial FEM model to the final calibrated model, and a reduction of $29 \%$ for the second natural frequency; considerable changes in the form of the $1^{\text {st }}$ and $2^{\text {nd }}$ mode shapes. With respect to differences in the static behavior of the structure, results showed: a $25 \%$ increase in tower top displacement; the compression force is the one with the smaller differences, with an increase of around $14 \%$ to $18 \%$ in maximum and minimum values; the major differences in calculated values occur in the base shear and the base moment values, with increases ranging from $8500 \%$ to $20200 \%$ but maintaining the location of the points of maximum stresses.

These results show the importance and the need of calibrating FEM numerical models to properly represent the real dynamic behavior of the steel structures. 


\section{ACKNOWLEDGEMENTS}

This paper is within the scope of the first author's Ph.D. degree in progress, financially supported by the Portuguese Foundation for Science and Technology (FCT) through the PhD grant reference SFRH/BD/147789/2019 under the programme POCH (N2020 - P2020) and subsidized by the European Social Fund (FSE) and national funds from MCTES. This work was financially supported by: Base Funding - UIDB/04708/2020 of the CONSTRUCT - Instituto de I\&D em Estruturas e Construções - funded by national funds through the FCT/MCTES (PIDDAC).

\section{REFERENCES}

[1] I. Roselli, M. Malena, M. Mongelli, N. Cvalagli, M. Gioffrè, G. Canio, G. Felice, Health assessment and ambient vibration testing of the 'Ponte delle Torri' of Spoleto during the 2016-2017 Central Italy seismic sequence, Journal of Civil Structural Health Monitoring, Vol. 8, 2, 199-216, 2018, doi: 10.1007/s13349-018-0268-5..

[2] A. Brencich, D. Sabia, Experimental identification of a multi-span masonry bridge: The Tanaro Bridge. Construction and Building Materials, Vol. 22, 10, 2087-2099, 2008, doi: 10.1016/j.conbuildmat.2007.07.031.

[3] H. Wang, A. Q. Li, J. Li, Progressive finite element model calibration of a long-span suspension bridge based on ambient vibration and static measurements, Enginering ans Strucutres, vol. 32, 9, 2546-2556, 2010, doi: 10.1016/j.engstruct.2010.04.028.

[4] G. Boscato, A. Dal Cin, Experimental and numerical evaluation of structural dynamic behavior of Rialto Bridge in Venice. Journal of Civil Structures and Health Monitoring, vol. 7, 4, p 557-572, 2017, doi: 10.1007/s13349-017-0242-7.

[5] D. Ribeiro, P. Jorge, C. Costa, R. Silva, A. Arêde, and R. Calçada, Calibração experimental de modelos numéricos de pontes ferroviárias em alvenaria de pedra. XXXVII Iberian Latin American Concress on Computational Methods in Engineering, 20,2016

[6] B. Sevim, A. Bayraktar, A. C. Altuniik, S. Atamtürktür, F. Birinci, Finite element model calibration effects on the earthquake response of masonry arch bridges. Finite Element Analisys and Design., vol. 47, 7, 621-634, 2011, doi: 10.1016/j.finel.2010.12.011.

[7] A. C. Altunişika, A. Bayraktar, B. Sevima, F. Birincia, Vibration-based operational modal analysis of the mikron historic arch bridge after restoration. Civil Engineering and Environmental Systems, vol. 28, 3, 247-259, 2011, doi: 10.1080/10286608.2011.588328.

[8] C. E. Ventura, J.F. Lord, and R. D. Simpson, Effective Use of Ambient Vibration Measurements for Modal Updating of a 48 Storey Building in Vancouver, Canada. International Conference on Structural Dynamics Modeling-Test, Analysis, Correlation and Validation, 1-10, 2002.

[9] M. Baptista, P. Mendes, A. Costa, A. Afilhado, P. Silva, C. Oliveira, Análise experimental para a obtenção das características dinâmicas do edifício da Portugal Telecom no Parque das Nações, $6^{\circ}$ Congresso Nacional de Sismologia e Engenharia Sísmica - Sísmica 2004, Aveiro, Portugal, vol. 2, 1-9, 2004. 
[10] M. Pieraccini, D. Dei, M. Betti, G. Bartoli, G. Tucci, N. Guardini, Dynamic identification of historic masonry towers through an expeditious and no-contact approach: Application to the 'Torre del Mangia' in Siena (Italy). Journal of Cultural Heritage, vol. 15, 3, 275282, 2014, doi: 10.1016/j.culher.2013.07.006.

[11] A. Demir, H. Nohutcu, E. Ercan, E. Hokelekli, G. Altintas, Effect of model calibration on seismic behaviour of a historical mosque. Structural Engineering and Mechanics, vol. 60, 5, 749-760, 2016, doi: 10.12989/sem.2016.60.5.749.

[12] M. Pavlovic, S. Trevisani, A. Cecchi, A Procedure for the Structural Identification of Masonry Towers, Journal of Nondestructive Evaluation, vol. 38, 2, 1-12, 2019, doi: 10.1007/s10921-019-0575-8.

[13] M. Girardi, C. Padovani, D. Pellegrini, L. Robol, A finite element model updating method based on global optimization. Mechanical Systems and Signal Processing 107372, 2020, doi: 10.1016/j.ymssp.2020.107372.

[14] G. Saudi, Structural assessment of a guyed mast through measurement of natural frequencies. Engineering Structures, vol. 59, 104-112, 2014, doi: 10.1016/j.engstruct.2013.09.049.

[15] A. F. Mensah, L. Dueñas-Osorio, Improved reliability of wind turbine towers with tuned liquid column dampers (TLCDs). Structural Safety. vol. 47, 78-86, 2014, doi: 10.1016/j.strusafe.2013.08.004.

[16] M. A. Lackner, M. A. Rotea, Passive structural control of offshore wind turbines. Wind Energy, vol. 14, 373-388, 2011, doi: 10.1002/we.

[17] G. Oliveira, F. Magalhães, A. Cunha, E. Caetano, Dynamic monitoring system for utility-scale wind turbines: damage detection and fatigue assessment. Journal of Civil Structures and Health Monitoring, vol. 7, 5, 657-668, 2017, doi: 10.1007/s13349-0170250-7.

[18] B. Fitzgerald, B. Basu, Active tuned mass damper control of wind turbine nacelle/tower vibrations with damaged foundations. Key Engineering Materials, vol. 569-570, 660667, 2013, doi: 10.4028/www.scientific.net/KEM.569-570.660.

[19] H. Zuo, K. Bi, H. Hao, Using multiple tuned mass dampers to control offshore wind turbine vibrations under multiple hazards. Engineering Structures, vol. 141, 303-315, 2017, doi: 10.1016/j.engstruct.2017.03.006.

[20] T. Gentils, L. Wang, A. Kolios, Integrated structural optimisation of offshore wind turbine support structures based on finite element analysis and genetic algorithm. Applied Energy, vol. 199, 187-204, 2017, doi: 10.1016/j.apenergy.2017.05.009.

[21] Y. Y. Ko, A simplified structural model for monopile-supported offshore wind turbines with tapered towers. Renewable Energy, vol. 156, 777-790, 2020, doi: 10.1016/j.renene.2020.03.149.

[22] Z. Zhang, A. Staino, B. Basu, S. R. K. Nielsen, Performance evaluation of full-scale tuned liquid dampers (TLDs) for vibration control of large wind turbines using real-time hybrid testing. Engineering Structures, vol. 126, 417-431, 2016, doi: 10.1016/j.engstruct.2016.07.008. 
[23] F. Castellani, D. Astolfi, M. Becchetti, F. Berno, F. Cianetti, A. Cetrini, Experimental and numerical vibrational analysis of a horizontal-axis micro-wind turbine. Energies, vol. 11, 2, 2018, doi: 10.3390/en11020456.

[24] CEN, Eurocódigo 3 - Projecto de estruturas de aço Parte 1-1: Regras gerais e regras para edifícios. 2010.

[25] M. E. Arslan, A. Durmuş, Modal testing and finite element model calibration of in-filled reinforce concrete frames. JVC/Journal Vibration and Control, vol. 20, 13, 1946-1959, 2014, doi: 10.1177/1077546313480545.

[26] CEN, Eurocode 3 - Design of steel structures - Part 1-6: Strength and Stability of Shell Structures, 2007.

[27] DNV/Risø, Guidelines for Design of Wind Turbines. Denmark, 2002. 